\title{
The evidence base in acute pain
}

\section{Andrew Moore}

Pain Research Unit, The Churchill, Oxford, UK

Medical research abounds in myths, legends, experience and various levels of evidence. One of the key elements in trying to pick our way through the labyrinth between us and the 'truth' is how to decide what we are dealing with at any time. Is the basic philosophy of what we are examining correct? Can clinical trials measure what they claim to measure? Isn't meta-analysis just some sophisticated statistical mumbo-jumbo covering up the old adage of 'garbage in-garbage out'? In acute pain we can answer most if not all of these questions, and be reasonably confident that the light at the end of the tunnel is not just an oncoming train.

\section{Philosophy}

Faced with pain studies for the first time the response of many people is to ask how it is possible to measure pain in the first place. Pain is subjective. One person's pain is another's irritation. That may be so, but we have been standing on the shoulders of the great in pain research for about 50 years ${ }^{1,2}$.

Measurement of pain intensity and pain relief using verbal categorical scales or visual analogue scales has been standardised. In a classic trial in acute pain the same nurse will administer the same scales to the same patient in the same way over intervals of about $6 \mathrm{~h}$. Patients can enter the trial in the first place only if they have pain of moderate or severe intensity: after all, if there is no pain, the effect of an analgesic cannot be measured.

\section{Clinical trials}

The design of clinical trials in acute pain is again grounded in good scientific method. The need for randomisation to avoid selection bias, and of blinding to avoid observer bias was obvious. But there are also major issues about trial validity. Sensitivity of the models used was demonstrated using placebo and standard analgesics, or by demonstrat- ing a difference between two doses of an analgesic.

Clinical trials of standard valid design and proven sensitivity can therefore indicate that a drug or intervention is an analgesic ${ }^{3}$. What single clinical trials often fail to do is to inform us about how good an analgesic is in comparison with another analgesic. The problem is that different trials sometimes tell us different things: in one a particular analgesic may look particularly efficacious, but in another barely do better than placebo. To try to overcome and to understand this variability we turn to systematic reviews and meta-analysis.

\section{Systematic review}

Critical to the validity of systematic reviews and meta-analysis are the issues of quality and size.

Quality comes in a number of guises. First is the issue of completeness. For reviews to be systematic, they have to try to find all the studies that might contribute to answering a particular clinical question. This used to be a task of heroic proportions, but is now much easier, both for pain in general and dentistry in particular. The Cochrane Library contains over 250,000 con- trolled trials, many obtained by handsearching for pain studies ${ }^{4}$. One of the major ongoing efforts of the Cochrane Collaboration is to make reports of relevant studies easier to find. As an example, the Oral Health group is handsearching 28 journals in the field of dentistry.

The second issue is the choice of studies to be included. In pain we have evidence that non-randomised ${ }^{5}$ and non-blinded ${ }^{6}$ studies overestimate the effects of treatment, and, consequently, systematic reviews should either exclude such studies, or at least perform sensitivity analysis to demonstrate the extent to which bias is occurring. In the three reviews abstracted in this issue of Evidence-Based Dentistry, the trials included were all randomised, all doubleblind, all with patients who had pain of moderate or severe initial intensity, and with the same outcome of at least half pain relief measured over the same time. Most of the studies were in pain after third molar removal, but analysis of the largest single dataset in acute pain, that for aspirin, has shown that dental pain is no different from other acute pain models ${ }^{7}$. In simple terms, this is not a question of apples being compared with oranges, but Cox's Orange Pippins with Cox's Orange Pippins.

It is useful to compare this approach with that of a review of acupuncture in dental pain ${ }^{8}$. It has been pointed out ${ }^{9}$ that, of the 16 trials, five were not randomised, two were not blind, three were very small (fewer than 10 patients). Of the remainder, two were in experimental pain, one had an inadequate placebo, leaving three trials with 110 patients with different outcomes at different times. 


\section{Outcomes and outputs}

There are still unresolved issues about the outcomes chosen and the way in which results are described. The choice of at least half pain relief is pragmatic, because what is missing is the patient perspective. We have failed to ask patients what degree of pain relief is adequate in what situations, and therefore failed to validate our outcome. This is not particular to pain studies, and is a hangover from the way in which research used to be done, but it is something that needs addressing in future.

Statistics are important to demonstrate that the differences we see between interventions - here between analgesic and placebo - are real. That information is less useful when we want to know not just that each of three treatments is analgesic, but how they compare one with the other. The number needed to treat, the reciprocal of the absolute proportion of patients achieving the outcome, is more useful, and is the best understood way of describing results for $\mathrm{GPs}^{10}$. This may be good enough for now, but the requirement remains for simple and understandable descriptions of the results so that they can be used with confidence in everyday practice.
Size

In all our concerns about trial design or meta-analytic principles, the easiest thing to forget about is the random play of chance. Trials powered to demonstrate that a drug is better than placebo are about 10 times too small to describe adequately how much better than placebo it is ${ }^{11}$. The most powerful argument for systematic review and meta-analysis is that conventional clinical trials are at the mercy of simple random effects.

These random effects in small numbers of patients are where the myths and legends begin. For the most commonly used analgesics in acute pain, we now have been able to gather together large amounts of information of the highest quality, and relevant to the patients we treat. We can trust it.

1. Keele KD. The pain chart. Lancet 1948; 2:6-8.

2. Wallenstein SL, Heidrich IG, Kaiko R, House RW. Clinical evaluation of mild analgesics: the measurement of clinical pain. Br J Clin Pharmacol 1989; 10:319S-327S.

3. McQuay HJ, Moore RA. An evidencebased resource for pain relief. Oxford: Oxford University Press, March 1998.
4. Jadad AR, Carroll D, Moore A, McQuay H. Developing a database of published reports of randomised clinical trials in pain research. Pain 1996; 66:239-246.

5. Carroll $D$, Tramèr $M$, McQuay $H$, Nye $B$, Moore A. Randomization is important in studies with pain outcomes: systematic review of transcutaneous electrical nerve stimulation in acute postoperative pain. $\mathrm{Br} \mathrm{J}$ Anaesthesia 1996; 77:798-803.

6. Ernst E, White AR. Acupuncture for back pain: A meta-analysis of randomised controlled trials. Arch Intern Med 1998; 158:2235-2241.

7. Edwards JE, Oldman A, Smith L, Wiffen PJ, Carroll D, McQuay HJ, Moore RA. Oral aspirin in postoperative pain: a quantitative systematic review. Pain 1999; 81:289-297.

8. Ernst $\mathrm{E}$, Pittler MH. The effectiveness of acupuncture in treating acute dental pain: a systematic review. Br Dent J 1998; 184:443-447.

9. Smith $\mathrm{L}$, Oldman A. Acupuncture in dental pain. Br Dent J 1999; 186:158-159.

10. McColl $A$, Smith $H$, White $P$, Field J. General practitioners' perceptions of the route to evidence based medicine: a questionnaire survey. Br Med J 1998; 316:361-365.

11. Moore RA, Gavaghan D, Tramèr MR, Collins SL, McQuay HJ. Size is everything large amounts of information are needed to overcome random effects in estimating direction and magnitude of treatment effects. Pain 1998; 78:209-216. 